\title{
STRATEGI KOMUNIKASI PEMERINTAH KABUPATEN BLORA MENUJU SMART CITY
}

\author{
Nisrina Meitibellina \\ Program Studi Ilmu Komunikasi, Universitas Islam Indonesia, Sleman, \\ Yogyakarta, Indonesia \\ Email:16321137@students.uii.ac.id \\ Puji Hariyanti \\ Program Studi Ilmu Komunikasi, Universitas Islam Indonesia, Sleman, \\ Yogyakarta, Indonesia. \\ Email: puji.hariyanti@uii.ac.id
}

\begin{abstract}
Article Info
Article History

Received

19 Nov 2020

Revised

24 Nov 2020

Accepted

26 Nov 2020

Abstract. This study discusses the communication strategy carried out by Blora Regency Government in the program of the Ministry of Communication and Information, namely Gerakan Menuju Smart City 2018. There are two statements in this research is how the communication strategy carried out by Blora Regency Government towards smart city and the factors that are driving and inhibiting it.The results obtained from Gerakan Menuju 100 Smart City program in Blora Regency are based on a predetermined policy in the form of the RPJMD and the Decree of the Regent. Then proceed with analyzing problems related to city problems to create the concept of smart city that requires 3 elements namely structure, infrastructure and superstructure. The targets for this program are all OPD's and the Blora community. The use of various media for socialization which then its implementation refers to the 2018 smart city master plan and ends with monitoring and evaluation every 2 times a year. There are 6 dimensions of the concept of smart city along with several activities in it that are used in Blora Regency, namely smart governance, smart branding, smart economy, smart living, smart society and smart environment.
\end{abstract}

Keywords: communication strategy, gerakan menuju 100 smart city, Blora Regency

\begin{abstract}
Abstrak. Program Gerakan Menuju 100 Smart City di Kabupaten Blora didasarkan pada kebijakan yang telah ditetapkan dalam bentuk RPJMD dan Keputusan Bupati. Kemudian dilanjutkan dengan menganalisa permasalahan yang berkaitan dengan permasalahan kota untuk membuat konsep smart city yang membutuhkan 3 elemen yaitu struktur, infrastruktur dan suprastruktur. Sasaran program ini adalah semua OPD dan komunitas Blora. Penggunaan berbagai media sosialisasi yang kemudian pelaksanaannya mengacu pada masterplan smart city 2018 dan diakhiri dengan monitoring dan evaluasi setiap 2 kali dalam setahun. Terdapat 6 dimensi konsep smart city beserta beberapa aktivitas di dalamnya yang digunakan di Kabupaten Blora yaitu smart governance, smart branding, smart economy, smart living, smart society dan smart environment.
\end{abstract}

Kata Kunci: Strategi Komunikasi, Gerakan menuju 100 smart city, Kabupaten Blora 


\section{PENDAHULUAN}

Smart City merupakan sebuah kota dapat mengontrol serta memperbaiki kondisi infrastruktur wilayahnya seperti jalan, rel, pelabuhan, bandara, sampai bangunan pemerintahannya agar dapat meningkatkan pelayanan warga, sumber daya serta keamanan (Esabella, 2016). Kurang lebih satu dekade belakangan, ini telah menjadi topik yang banyak dibahas, dan menginspirasi banyak kebijakan termasuk di Indonesia. Sejak 2015, Indonesia telah merancang smart city yang diawali di Kota Jakarta. Namun, baru 2018, gerakan smart city baru mulai dirancang secara masif, dan sejak itu pula pemerintah mulai memberikan penghargaan kepada kota-kota yang berhasil mengembangkan smart city. Kabupaten Blora didaulat sebagai teladan dalam mengimplementasikan program Gerakan Menuju 100 Smart City 2018.

$2018 \begin{gathered}\text { Gerakan Menuju } 100 \text { Smart City } \\ \text { memiliki enam elemen }\end{gathered}$
pembangunan, yakni smart governance, smart branding, smart economy, smart living, smart society, dan smart environment. Smart Governance menjadi pilar dasar dalam smart city sekaligus memiliki peran sebagai mesin yang mendorong semua elemen smart city lainnya. Terdapat tiga fungsi governance yang harus diterapkan dalam smart governance, yakni tata kelola birokrasi, pelayanan publik serta kebijakan publik. Smart Branding, di sisi lain, menjadi elemen kedua dalam model Smart City. Ini bertujuan untuk meningkatkan nilai dari suatu kota atau daerah untuk masyarakat, para wisatawan, dan pemilik bisnis. Tiga sifat yang terdapat pada smart branding adalah pariwisata, bisnis dan citra daerah.

Elemen ketiga dalam model smart city yang menjadi fungsi utama untuk suatu kota/daerah dalam menyusun sistem ekonomi yang smart, pembangunan wilayah industri dengan tepat, memajukan kesejahteraan masyarakat, serta mempersiapkan struktur transaksi yang lancar. Smart living menggambarkan kawasan lingkungan berupa perumahan dengan fasilitas memadai untuk warganya. Selain itu, untuk memudahkan mobilitas penduduk, sebuah kota (daerah) harus mampu menyediakan sarana transportasi publik ataupun pribadi, membantu kelancaran mobilitas logistik, serta pelayanan kesehatan yang terjamin bagi penduduknya.

Smart Society merujuk pada hubungan masyarakat sosial, individu, serta digital di mana masing-masing individu di tengah masyarakat diharuskan mengakses pendidikan dengan fasilitas pendukung secara digital. Selain itu, pemerintah melakukan proteksi pada keselamatan jiwa, risiko bencana bagi warga serta properti. Smart Environment, di sisi lain, merujuk bahwa suatu kota (daerah) berkewajiban dalam melestarikan lingkungan, pengelolaan limbah, dan pemanfaatan energi sehingga dapat menopang semua kehidupan ekosistem yang ada.

Dengan merujuk enam indikator di atas, dapat dikatakan bahwa tidaklah gampang untuk membangun smart city karena banyak dimensi atau elemen yang harus diperhatikan. Strategi komunikasi yang efektif karenanya sangat diperlukan. Cangara (2013) mendefinisikan strategi komunikasi sebagai perpaduan atas segala elemen komunikasi dari komunikator, pesan, media (saluran), penerima hingga pengaruh (efek) demi memaksimalkan tujuan komunikasi. Menurut Cangara (2013), penentuan strategi menjadi langkah yang penting sehingga membutuhkan penyelesaian yang cermat untuk perencanaan komunikasi. Menurut Effendy (Lianjani, 2018), strategi 
komunikasi adalah perpaduan dari communication planning (perencanaan komunikasi) serta communications management (komunikasi manajemen) agar target yang diinginkan tercapai.

Strategi komunikasi adalah perpaduan seluruh elemen komunikasi dari komunikator, pesan, media (saluran), penerima hingga pengaruh (efek) guna mewujudkan maksimalnya tujuan komunikasi. Penentuan strategi menjadi langkah yang penting sehingga membutuhkan penyelesaian secara hatihati dalam perencanaan komunikasi (Cangara, 2013).

Menurut Wayne Pace, Brent D, Peterson, serta Dallas Burnett, strategi komunikasi memiliki tujuan (Lianjani, 2018) adalah meyakinkan bahwa sasaran/komunikan memahami apa yang ia terima (to secure understanding), penerimaan pesan oleh komunikan itu kelak akan dibina (to establish acceptance), hingga tindakan di motivasikan (to motivate action)

Penetapan strategi untuk perencanaan komunikasi tidak luput dari adanya elemen komunikasi. Menurut Lasswell (dalam Wijaya, 2015), komunikasi dapat menjawab pertanyaan berupa who says what in which channel to whom with what effect Maka dari itu, perencanaan komunikasi menerapkan strategi sebagai berikut (Wijaya, 2015).

a. Menentukan komunikator. Peran komunikator sangat penting sebagai pelaku utama dalam kegiatan komunikasi. Komunikator memiliki syarat yang harus dimiliki seperti kredibilitas, kekuatan, dan daya tarik

b. Menentukan target sasaran/ khalayak. Dalam hal ini, kegiatan komunikasi memahami masyarakat atau target sasaran adalah hal yang penting.

c. Merumuskan pesan. Pesan yakni segala sesuatu yang disampaikan berupa bentuk simbol serta tersampaikan oleh komunikan. Adapun 3 sifat pesan, yakni informatif, persuasif dan edukatif. Pesan informatif berarti sekadar ingin diketahui masyarakat, sedangkan persuasif jika pesan tersebut ingin mengajak/memengaruhi publik. Pesan edukatif memiliki unsur kognitif, afektif dan psikomotorik.

d. Menentukan saluran serta media komunikasi. Media harus memerhatikan karakter dan isi yang disampaikan ke khalayak dan pesan yang disalurkan kepada seluruh masyarakat dapat dijangkau via media massa

e. Efek/pengaruh komunikasi. Tujuan seluruh kegiatan komunikasi yang dilaksanakan adalah memberikan pengaruh kepada khalayak ke dalam pola perubahan pada pengetahuan, sikap serta perilaku,

Cangara (2013) menyatakan bahwa tahapan perencanaan komunikasi meliputi lima tahapan (model perencanaan komunikasi lima langkah) yakni sebagai berikut, yakni penelitian, perencanaan, pelaksanaan, evaluasi, dan pelaporan. Penelitian (research) dimaksudkan untuk memahami permasalahan yang menimpa suatu lembaga. Permasalahan bisa berupa wabah penyakit, kerugian perusahaan, dan lain sebagainya. Tahapan ini juga berarti menemukan/mencari fakta untuk ditetapkan menjadi rumusan dalam pembuatan strategi komunikasi untuk lembaga/organisasi agar tercapai tujuannya. 
Plan (perencanaan) yakni respon yang diterima sesudah terdapat hasil penelitian, perencanaan komunikasi ini juga membutuhkan strategi terkait penetapan sumber (komunikator), pesan, media, sasaran, serta efek. Pelaksanaan (execute) adalah tindakan dalam mengimplementasikan perencanaan komunikasi yang telah ditetapkan. Pelaksanaan dapat berupa tanya jawab di radio, tayangan televisi, promosi di surat kabar/koran, mendirikan baliho/spanduk, stiker yang dibagikan pada sasaran atau tim yang ditunjuk untuk melakukan penyuluhan dengan komunitas di tempat target sasaran. Evaluasi (measure) dilakukan agar diketahui hasil akhir dari program yang telah dilakukan. Terakhir adalah pelaporan (report). Pada tahap ini, laporan lebih baik dibuat tertulis untuk disampaikan pada pimpinan agar menjadi bahan pertimbangan. Jika program tersebut berhasil maka bisa menjadi pedoman untuk program selanjutnya, sebaliknya jika kurang sempurna program tersebut dapat direvisi.

Penelitian terkait smart city sudah pernah dilakukan dengan mengambil objek penelitian Kota Malang (Purnomowati, 2014) di mana penelitian ini menunjukkan bahwa dalam rangka mewujudkan konsep smart city telah dipersiapkan dengan baik oleh pemerintah Kota Malang melalui SDM dan Ilmu pengetahuan dan teknologi (Iptek). Penelitian di Kota Bandung yang dikemukakan oleh Mursalim (2017) menunjukkan bahwa Kota Bandung menerapkan peraturan smart city sendiri dalam sosialisasinya masih belum merata kepada masyarakat dan SKPD sehingga proses pembangunan smart city dibutuhkan waktu yang lama. Hal ini perlu dukungan dari pemerintah serta masyarakat Bandung. Penelitian smart city juga di Kota Banjarmasin yang dilakukan Ulya \& Tarigan (2017).
Penelitian tersebut menunjukkan bahwa ada tiga faktor enabler, yakni tata kelola SC, TIK (Teknologi Informasi dan Komunikasi), dan manusia.

Penelitian ini akan mengkaji lebih dalam mengenai strategi komunikasi yang dilaksanakan oleh pemerintah Kabupaten Blora untuk program Gerakan Menuju 100 Smart City. Penelitian juga akan mengeksplorasi faktor pendukung dan penghambat pemerintah Kabupaten Blora dalam mengimplementasikannya. Penelitian ini menggunakan konsep dari Citiasia Smart City karena disesuaikan dengan kondisi Kabupaten Blora yang membutuhkan enam elemen tersebut dari smart government, smart branding, smart economy, smart living, smart society, dan smart environment untuk menuju smart city. Selain itu, Citiasia menjadi salah satu tim ahli bersama praktisi lainnya yaitu UI, ITB. UGM, Perbanas. BPPT. INSW, dan KTII dalam mewujudkan Gerakan Menuju 100 Smart City yang mana Kabupaten Blora termasuk di dalamnya.

\section{METODE}

Peneliti menggunakan metode penelitian dengan pendekatan kualitatif eksploratif. Alasan menggunakan penelitian eksploratif karena penulis ingin memperdalam serta menjabarkan kondisi suatu objek yang berhubungan dengan manajemen atau pengelolaan SDM (Sumber Daya Manusia) di Kabupaten Blora terkait dengan upaya mewujudkan Gerakan Menuju 100 Smart City.

Penelitian lapangan berlangsung dari bulan September sampai Desember 2019 di Dinas Komunikasi dan Informasi Kabupaten Blora. Selama di lapangan, peneliti mencatat setiap kejadian dan kegiatan yang diamati serta menggunakan 
recorder (alat perekam) untuk wawancara dan kamera untuk keperluan dokumentasi.

Pengumpulan data primer berupa wawancara untuk menerima informasi dari para narasumber terkait topik smart city. Selain itu, peneliti membutuhkan data lain/data sekunder sebagai sumber tambahan berupa pamflet, majalah, video, dan lain-lain (jika ada) mengenai Gerakan 100 Menuju smart city Kabupaten Blora.

Peneliti mengaplikasikan model analisis data interaktif Miles dan Huberman yang terdapat 3 bagian, yakni (1) reduksi data (2) penyajian data dan (3) verifikasi/penarikan kesimpulan. Menurut Miles dan Huberman (Idrus, 2009). Tiga kegiatan tersebut dilakukan saat mengumpulan data dan proses ini juga disebut sebagai siklus dan interaktif. Jadi, peneliti bergerak dalam tiga tahap, yakni pengumpulan data, penyajian data, reduksi data dan verifikasi/kesimpulan. Maka dari itu, bisa dikatakan bahwa analisis yang digunakan akan terus berulang dan berlanjut hingga saat penulisan akhir dilaksanakan.

\section{HASIL DAN PEMBAHASAN}

\section{Kebijakan Komunikasi Pemerintah Kabupaten Blora Menuju Smart City}

Data diperoleh dari dokumen Rencana Pembangunan Jangka Menengah Daerah (RPJMD) Kabupaten Blora tahun 2016-2021 serta Keputusan Bupati Blora nomor 555/395/2018 tentang pembentukan tim pelaksana smart city di Kabupaten Blora tahun 2018. Adanya SK Bupati merupakan bentuk dukungan Bupati Blora terhadap program Gerakan Menuju 100 smart city

Kebijakan komunikasi, menurut Cangara (2013), sebelum mengimplementasikan suatu kegiatan, kebijakan sebagai dasar dalam perencanaan. Kebijakan merupakan pedoman sedangkan perencanaan dalam realisasinya didasarkan atas petunjuk yang telah ditetapkan sehingga perencanaan harus berpegang teguh pada kebijakan. Dalam temuan penelitian ini, perencanaan kegiatan Gerakan Menuju 100 smart city di Kabupaten Blora berpatokan pada peraturan-peraturan yang sudah diputuskan.

\section{Strategi Komunikasi Pemerintah Kabupaten Blora Menuju Smart City}

Subbab ini menjabarkan elemen komunikasi dalam strategi komunikasi yang dilakukan oleh pemerintah Kabupaten Blora mana terbagi dalam beberapa tahapan, yakni penelitian, perencanaan, pelaksanaan, dan evaluasi.

\section{Penelitian}

Proses sebuah kota/kabupaten untuk terpilih dalam mengimplementasikan Gerakan 100 Menuju smart city ini juga melewati tahap menganalisis masalah. Permasalahan yang timbul saat ini, yaitu meningkatnya permasalahan kota sejalan dengan total populasi penduduk yang berlebih dan berbanding lurus dengan kepentingan ekonomi maupun non ekonomi. Oleh karena itu, untuk menurunkan persoalan-persoalan tersebut, diperlukan solusi cerdas yang menggunakan teknologi terdepan agar efisiensi dan kualitas mengalami peningkatan serta memperkecil biaya. Solusi tersebut dibuat dalam sebuah konsep, yakni smart city. Dalam mengimplementasikan program Gerakan Menuju smart city tersebut, dibutuhkan 3 elemen, yakni struktur, infrastruktur, dan suprastruktur atau disebut kajian Smart Readiness yang termuat di Masterplan smart city (Pemkab Blora, 2018) 
Pemkab Blora dalam menentukan ketiga elemen tersebut melalui proses pengumpulan data selama kurang lebih 3 bulan bersama pihak-pihak yang terlibat seperti perwakilan masing-masing OPD, akademisi, serta masyarakat. Diawali dengan data RPJMD dari Bappeda, dilanjutkan oleh penyerahan data masingmasing OPD yang akan diteliti lebih lanjut.

Adapun tujuan yang ingin dicapai Pemerintah Kabupaten Blora dalam melaksanakan program Gerakan Menuju 100 Smart City sebagaimana tertulis dalam Masterplan smart city (Pemkab Blora, 2018) Kabupaten Blora diantaranya sebagai berikut.

a. Memajukan kapabilitas, keterampilan, etos kerja serta kredibilitas ASN (Aparatur Sipil Negara)

b. Membangun responsibilitas kinerja Pemerintah Daerah serta memanfaatkan perkembangan IPTEK untuk peningkatan kualitas pelayanan publik

c. Membangun pertumbuhan ekonomi serta melakukan pemerataan pendapatan masyarakat

d. Memajukan prestasi dan mengapresiasi pemuda dan olahraga serta seni budaya daerah dengan memanfaatkan IPTEK

e. Membangun kualitas dan kuantitas infrastruktur

Saat Kabupaten Blora menjalani seluruh proses seleksi, sebelum terpilih dalam Gerakan Menuju 100 Smart City, diantaranya mengirimkan beberapa data pendukung seperti pendapatan per kapita, jumlah penduduk, tingkat pendidikan, potensi yang ada di Blora dan lain-lain. Kemudian, Blora juga memiliki beberapa indikator lain yang memenuhi sehingga akhirnya terpilih dalam 50 kota/kabupaten yang masuk dalam program tersebut pada 2018. Indikator lainnya, yakni menentukan Smart Readiness yang digunakan untuk penyusunan masterplan smart city meliputi struktur, infrastruktur, dan suprastruktur

\section{Perencanaan}

Perencanaan, menurut Hariadi (Lianjani, 2018), yakni perancangan metode-metode ke depan dalam menentukan dan merancang strategi agar suatu tujuan strategis tersebut tercapai. Perencanaan (Cangara, 2013) merupakan aksi yang akan digunakan setelah mendapatkan hasil penelitian. Sehingga tahap perencanaan dalam program Gerakan Menuju 100 Smart City dibutuhkan strategi mengenai penetapan komunikator, pesan, media, sasaran, serta efek yang diinginkan.

\section{a. Komunikator}

Komunikator adalah seseorang yang menyatakan pesan dan penting sebagai bagian dari aktivitas komunikasi. Pihak yang menjadi komunikator dalam program Gerakan Menuju 100 smart city di Kabupaten Blora, yaitu semua dinas yang terkait dalam program tersebut salah satunya Dinkominfo Blora dalam hal menyosialisasikan TIK kepada masyarakat Blora. E-retribusi oleh Dinas Perdagangan Koperasi, Usaha Kecil dan Menengah (smart economy) dan lain- lain sehingga semua dinas yang terlibat dalam program Gerakan Menuju 100 smart city menjadi komunikator untuk menyampaik informasi sesuai dengan kegiatan-kegiatan yang telah disusun dalam setiap dimensi smart city. 


\section{b. Pesan}

Pesan adalah segala sesuatu yang tersampaikan dalam bentuk simbol dan diterima oleh komunikan. Pemkab Blora lewat dinas-dinas terkait memiliki peran sebagai komunikator untuk menyajikan informasi tentang program Gerakan Menuju 100 Smart City dari segi kegiatankegiatan di dalamnya dari 6 dimensi smart city kepada masyarakat Blora agar dapat menambah wawasan baru tentang smart city. Dengan begitu, dapat membantu Pemkab Blora mewujudkan Blora smart city. Isi pesan atau informasi terkait smart city yang disampaikan kepada masyarakat Blora juga menyesuaikan media apa yang digunakan, misalnya, di media sosial seperti instagram berarti harus memuat informasi berupa foto-foto kegiatan beserta caption. Jika menggunakan radio, maka pesan yang disampaikan berupa suara.

Sifat pesan yang digunakan dalam beberapa medium tersebut adalah informatif. Dalam komunikasi antarmanusia, informasi berarti sesuatu yang didapat sebagai pengetahuan bagi seseorang. Seperti dikatakan informan, untuk sementara ini, penyampaian pesan terkait program Gerakan Menuju 100 Smart City masih bersifat informatif

\section{Pesan yang dibuat oleh Pemkab Blora mengenai program-program pemerintah untuk disampaikan kepada masyarakat luas rata-rata bersifat informatif. Isi pesan biasanya faktual atau baru serta umum berupa publikasi. Dalam komunikasi antarmanusia, informasi berarti sesuatu yang didapat sebagai pengetahuan bagi seseorang.}

\section{c. Media}

Media juga merupakan komponen yang penting dalam menyampaikan pesan sebagai penghubung ketika berkomunikasi (Lianjani, 2018). Media yang digunakan oleh Dinkominfo Blora untuk melakukan sosialisasi program Gerakan Menuju Smart City di Kabupaten Blora maupun penyebarluasan informasi hasil pembangunan adalah melalui media massa (radio, koran), media tradisional (pertunjukan rakyat), media interpersonal (sarasehan, ceramah/diskusi, lokakarya), media luar ruang (pamflet, brosur, baliho), serta media baru seperti website/portal online, dan media sosial (facebook, instagram, twitter). Pemanfaatan media sosial dirasa lebih efektif dan efisien karena banyaknya masyarakat yang memiliki media sosial sehingga dapat menjangkau khalayak.

\section{d. Sasaran}

Sasaran merupakan seseorang yang mendapatkan pesan yang telah disampaikan, bisa disebut komunikan. Sasaran kegiatan Gerakan Menuju 100 Smart City adalah seluruh OPD serta masyarakat Blora. Keikutsertaan pihakpihak yang menjadi target sasaran tersebut penting dalam penyampaian tujuan program tersebut sehingga pemahaman mengenai smart city semakin luas. Khalayak atau target yang dituju oleh Pemerintah Kabupaten Blora dalam kegiatan Gerakan Menuju 100 Smart City adalah seluruh OPD serta masyarakat Blora seperti yang dikatakan oleh para informan penelitian ini.

\section{e. Efek}

Efek adalah keputusan final dari kegiatan komunikasi untuk memengaruhi khalayak, bisa dalam bentuk perubahan pada pengetahuan, sikap serta perilaku. Dinkominfo Blora dalam penyampaian informasi mengenai program Gerakan Menuju 100 Smart City berupa aplikasi yang mempermudah pelayanan publik seperti Blora Kuncara yang memberikan pengaruh kepada masyarakat sehingga menjadi lebih paham akan teknologi informasi. Namun, proses sosialisasi 
program Gerakan 100 Menuju Smart City yang dilakukan oleh Pemkab Blora terutama Dinkominfo pada tahun pertama (2018- 2019) mempunyai beberapa kendala dan belum memberikan pengaruh yang signifikan karena sosialisasi yang kurang menyeluruh kepada masyarakat sehingga sebagian besar masyarakat belum paham terkait apa smart city itu. Di sisi lain, sifat masyarakat pada umumnya kurang tertarik akan konten yang disajikan oleh Pemkab Blora di media sosial karena mereka tidak membutuhkan informasi tersebut.

Kurangnya sosialisasi dari Pemkab Blora sesuai dari hasil wawancara peneliti dengan kelima perwakilan masyarakat, hanya satu orang saja yang mengetahui bahwa pemasangan wifi di ruang publik merupakan salah satu kegiatan penunjang smart city yang telah dilaksanakan. Keempat informan yang berstatus pelajar dan mahasiswa ini menyatakan hal yang sama bahwa mereka belum mengetahui istilah program Gerakan Menuju 100 Smart City di Kabupaten Blora, tetapi untuk semua informan mengaku sudah menikmati adanya layanan wifi di ruang publik tersebut.

\section{Pelaksanaan}

\section{Pemkab}

Blora

telah

menyosialisasikan program Gerakan Menuju 100 Smart City dengan fokus untuk memperkenalkan program-program yang mendukung Blora Smart City menggunakan bahasa/kalimat yang mudah dimengerti oleh masyarakat setempat. Dalam hal komunikasi yang terjalin di ruang lingkup Pemkab Blora berdasarkan hasil wawancara dengan narasumber, dibangun dengan baik seperti saat diadakan sosialisasi serta bimtek bersama OPD lain dan perwakilan beberapa tokoh masyarakat yang berjalan lancar sehingga tidak menjadi suatu masalah. Sedangkan di luar pemerintahan seperti dengan masyarakat, komunikasi yang dilakukan berupa door to door maupun menyapa lewat media sosial.

Implementasi program Gerakan Menuju 100 Smart City sudah memasuki tahun pertama pada 2019. Dalam hal ini, ada beberapa kegiatan yang telah dikerjakan di masing-masing dimensi, yakni smart governance, smart branding, smart economy, smart living, smart society dan smart environment. Keseluruhannya merupakan kegiatan yang dimuat dalam peta jalan/roadmap smart city. Dalam Masterplan (Pemkab Blora, 2018), dijelaskan bahwa roadmap adalah metode-metode yang harus dikerjakan oleh pemerintah daerah untuk merealisasikan Masterplan Smart City menjadi implementasi pembangunan. Implementasi pembangunan ini terbagi dalam 3 tahap, yaitu pembangunan jangka pendek pada tahun 2018 (1 tahun), jangka menengah tahun 2019-2022 (5 tahun) dan jangka panjang 2023-2028 (10 tahun). Dalam melaksanakan kegiatan belum tentu tercapai hingga 100\% karena bisa saja terjadi perubahan dari berbagai faktor salah satunya yakni anggaran.

Selain roadmap, terdapat pula quick win, yakni agenda pembangunan jangka pendek sekaligus menjadi program unggulan yang harus dirancang oleh pemerintah. Quick win ini berisi proyek yang berpengaruh langsung pada masyarakat. Pemkab Blora telah merancang 3 program usulan quick win serta mengembangkannya pada 2019. Ketiga usulan tersebut merupakan gabungan dari komponen smart city yakni sebagai berikut.

- Aplikasi Blora Kuncara (smart governance, smart economy)

- Smart Eco Village (smart economy, smart branding, smart 
environment)

- Aplikasi Sedot A Mas. (smart living, smart society)

\section{Evaluasi}

Hasil evaluasi terakhir di Jakarta, Kabupaten Blora mendapat rata-rata skor sebesar 2,9, dan mengalami sedikit penurunan dari evaluasi sebelumnya yang mendapat rata-rata 3,o. Penurunan skor pada evaluasi terakhir diperkirakan karena penyampaian data saat presentasi belum maksimal serta dokumentasi kegiatankegiatan smart city yang kurang lengkap sehingga penilaian yang didapat oleh Kabupaten Blora saat evaluasi menurun.

\section{Pelaporan}

Pelaporan terkait monitoring, belum terkelola dengan baik dan Pemkab Blora hanya melakukannya secara mandiri sebatas Dinkominfo memantau masing- masing OPD untuk melaksanakan dan melaporkan programnya.

\section{Konsep Smart City di Kabupaten Blora}

Berikut adalah 6 dimensi smart city beserta program yang telah direncanakan maupun yang sudah dilaksanakan oleh Pemerintah Kabupaten Blora.

\section{a. Smart Governance}

Smart governance dalam Masterplan Smart City (Pemkab Blora, 2018) memiliki tujuan untuk menciptakan tata kelola dan tata pamong pemerintahan daerah serta meningkatkan kinerja birokrasi dengan inovasi teknologi agar lebih komunikatif, efisien dan efektif. Hampir sebagian besar program-program untuk menunjang smart governance telah dilaksanakan oleh masing-masing OPD dalam satu tahun pertama sejak ditetapkan sebagai kabupaten yang masuk dalam Gerakan Menuju 100 Smart City pada 2018 (lihat tabel 1)

Tabel 1. Kegiatan smart governance tahun 2018-2019 dalam Masterplan

\begin{tabular}{|c|c|c|c|c|}
\hline No & NAMA KEGIATAN & PELAKSANA & 2018 & 2019 \\
\hline 1 & $\begin{array}{l}\text { Si Cantik (Aplikasi Cerdas Layanan Perizinan Terpadu Untuk } \\
\text { Publik) }\end{array}$ & DPMPTSP & $v$ & $v$ \\
\hline 2 & $\begin{array}{l}\text { PATEN (Pelayanan Terpadu Ke Kecamatan Untuk } \\
\text { Pengurusan IMB) (IUMK dan Administrasi Lainnya) }\end{array}$ & DPMPTSP & $v$ & v \\
\hline 3 & $\begin{array}{l}\text { E-KIOS (Anjungan Layanan Perizinan di Tingkat } \\
\text { Kecamatan) Meliputi : (Informasi Layanan, Pengaduan, } \\
\text { Cetak Formulir, Tracking Izin) }\end{array}$ & DPMPTSP & $v$ & $v$ \\
\hline 4 & $\begin{array}{l}\text { PAK REBO (Aplikasi Perhitungan Retribusi IMB) Berbasis } \\
\text { Android }\end{array}$ & DPMPTSP & $v$ & $v$ \\
\hline 5 & $\begin{array}{l}\text { E-samin (Sistem Informasi Administrasi Manajemen Pajak } \\
\text { Terintegrasi) }\end{array}$ & DPMPTSP & $v$ & $v$ \\
\hline 6 & SMS Gateway Pelayanan Perijinan & DPMPTSP & $v$ & $v$ \\
\hline 7 & Internet OPD Se Kab Blora & DINKOMINFO & & v \\
\hline 8 & Peningkatan Kapasitas Aparat Kependudukan dan Capil & DINDUKCAPIL & v & v \\
\hline 9 & Peningkatan SDM di Bidang Teknologi Informasi & DINKOMINFO & v & v \\
\hline 10 & Wifi/Hotspot Di Tempat Publik & DINKOMINFO & v & v \\
\hline 11 & $\begin{array}{l}\text { Informasi Pelayanan Administrasi Gratis Melalui Media } \\
\text { Massa }\end{array}$ & DINDUKCAPIL & v & v \\
\hline 12 & Pelayanan Hari Liburdan Car Free Day) & DINDUKCAPIL & $v$ & $v$ \\
\hline 13 & $\begin{array}{l}\text { Pelayanan AKUSEMOK (Administrasi Kependudukan Untuk } \\
\text { Semua OK) }\end{array}$ & DINDUKCAPIL & & v \\
\hline 14 & Pelayanan DISDUKCAPIL di Desa dan di Sekolah & DINDUKCAPIL & $v$ & $v$ \\
\hline 15 & SELINTAS (Sehari Lahir Akte Tuntas) & DINDUKCAPIL & v & v \\
\hline 16 & $\begin{array}{l}\text { Kerjasama Kementerian Agama Untuk Perubahan Status } \\
\text { Saat Menikah }\end{array}$ & DINDUKCAPIL & v & $v$ \\
\hline 17 & Pelayanan Cetak KTP Di Kecamatan & DINDUKCAPIL & v & v \\
\hline 18 & Papan Informasi Digital Di OPD & DINKOMINFO & & v \\
\hline 19 & Katalog Sembako & DINDAGKOPUKM & $v$ & $v$ \\
\hline
\end{tabular}




\begin{tabular}{|c|c|c|c|c|}
\hline NO & NAMA KEGIATAN & PELAKSANA & 2018 & 2019 \\
\hline 20 & Runing Text Harga Sembako & DINDAGKOP UKM & $v$ & $v$ \\
\hline 21 & Presensi Online & BKD & & v \\
\hline 22 & E-SKP (Sasaran Kerja Pegawai) & BKD & v & v \\
\hline 23 & SIMPEG (Sistem Informasi Pegawai) & BKD & v & v \\
\hline 24 & e-Office & DINKOMINFO & v & $v$ \\
\hline 25 & $\begin{array}{l}\text { Integrasi Sistem Informasi Daerah (Perencanaan, } \\
\text { Keuangan, eSakip dan eMonev) }\end{array}$ & DINKOMINFO & v & $v$ \\
\hline 26 & SPIPISE Untuk IP dan IU Penanaman Modal & DPMPTSP & $v$ & v \\
\hline 27 & Website Pelayanan Perijinan (dpmpts.blorakab.go.id) & DPMPTSP & v & v \\
\hline 28 & Sistem Informasi Peta Investasi Berbasis GIS & DPMPTSP & & v \\
\hline 29 & Penyediaan Sistem Informasi Bagi Perangkat Daerah & DINKOMINFO & v & v \\
\hline 30 & Penyediaan Data Center & DINKOMINFO & v & v \\
\hline 31 & Penyediaan Server Firewall (security) & DINKOMINFO & & $v$ \\
\hline 32 & Penyediaan Jaringan Fiber Optic & DINKOMINFO & & $v$ \\
\hline 33 & Dashboard Smart City Kabupaten Blora & DINKOMINFO & & $v$ \\
\hline 34 & Inventarisaasi Kode dan Data Wilayah (Koordinat) & BAG. TAPEM & & v \\
\hline 35 & $\begin{array}{l}\text { Sistem Informasi Inventaris Data Wilayah (Kec, Desa, } \\
\text { Jalan : Histori dan Koordinat) }\end{array}$ & BAG. TAPEM & & v \\
\hline 36 & $\begin{array}{l}\text { Integrasi Data Desa Sampai ke Tingkat Kabupaten (4 Desa } \\
\text { di Blora) }\end{array}$ & DPMD & & v \\
\hline 37 & Sistem Online Pelayanan Desa & DPMD & & v \\
\hline 38 & Publikasi Produk Hukum Yang Terintegrasi & BAG. HUKUM & v & v \\
\hline 39 & $\begin{array}{l}\text { e-SAKIP (Sistem Akuntabilitas Kinerja Instansi } \\
\text { Pemerintahan) }\end{array}$ & BAG. ORTALA & & v \\
\hline
\end{tabular}

Tabel 1 merupakan kegiatan untuk menunjang smart governance di Kabupaten Blora yang telah terlaksana dalam rentang 2018-2019, dan akan terus berlanjut serta tercantum dalam Masterplan (Pemkab Blora, 2018) bagian roadmap smart city. Contoh kegiatan yang telah diimplementasikan adalah wifi/hotspot di tempat publik yang sudah tersedia di beberapa tempat strategis seperti Alun-alun, Taman Tirtonadi, Taman Blora Super Blok, Taman Mustika, dan lain-lain. Wifi tersebut sudah bisa digunakan dan disambut baik oleh masyarakat Blora. Seperti dikatakan oleh para informan, pengguna wifi di salah satu tempat, yaitu Alun-alun Blora bahwa mereka memanfaatkan wifi untuk menghemat kuota sambil mencari informasi untuk tugas- tugas sekolah maupun hiburan untuk melepas penat. Lalu, di lokasi area wifi lainnya, yakni di Taman Tirtonadi, adanya wifi di sini selain untuk tempat nongkrong sambil internetan juga menguntungkan bagi para pengusaha warung makan karena taman tersebut menjadi ramai pengunjung.

\section{b. Smart branding}

Sasaran smart branding adalah meningkatkan brand value daerah untuk memajukan kegiatan perekonomian dan mengembangkan aktivitas sosial serta budaya setempat agar kesejahteraan masyarakat dapat bertambah (Pemkab Blora, 2018). 
Tabel 2. kegiatan smart branding 2018-2019 dalam Masterplan.

\begin{tabular}{|c|c|c|c|c|}
\hline NO & NAMA KEGIATAN & PELAKSANA & 2018 & 2019 \\
\hline 1 & Kalender Even KREATIF & DINPORABUDPAR & $\mathrm{v}$ & $\mathrm{v}$ \\
\hline 2 & Blora Car Free Day & DINPORABUDPAR & v & $v$ \\
\hline 3 & Festival Seni Budaya & DINPORABUDPAR & v & v \\
\hline 4 & $\begin{array}{l}\text { Lomba Tingkat Regional Dan Nasional Seni } \\
\text { Budaya dan Olahraga }\end{array}$ & DINPORABUDPAR & v & $\mathrm{v}$ \\
\hline 5 & Bus Pariwisata & DINPORABUDPAR & v & v \\
\hline 6 & Smart Village & DINPORABUDPAR & v & v \\
\hline 7 & Perbaikan Sarana Prasarana Pariwisata & DINPORABUDPAR & $\mathrm{v}$ & v \\
\hline 8 & Paket Wisata & DINPORABUDPAR & v & v \\
\hline 9 & Bimtek Pelaku Usaha Mendukung Pariwisata & DINPORABUDPAR & v & v \\
\hline 10 & $\begin{array}{l}\text { Pengembangan Bibit Unggul Pertanian (Lab } \\
\text { Alam) }\end{array}$ & DIPERTAN & v & v \\
\hline 11 & Sistem Informasi Pariwisata & DINPORABUDPAR & v & v \\
\hline 12 & Penataan Alun Alun Sebagai Landmark Kota & DPUPR & v & v \\
\hline 13 & Pembuatan Gapura Obyek Wisata & DINPORABUDPAR & v & v \\
\hline 14 & Videotron & DINKOMINFO & $\mathrm{v}$ & $\mathrm{v}$ \\
\hline 15 & Penunjuk Arah Digital & DINRUMKIMHUB & $\mathrm{v}$ & v \\
\hline
\end{tabular}

Smart branding memiliki 15 kegiatan yang salah satunya termasuk dalam Quick Win, yaitu Smart Eco Village yang pilot project-nya berada di Desa Kemiri, Kecamatan Jepon, Kabupaten Blora. Kegiatan Smart Eco Village memiliki potensi dalam mengembangkan peternakan, perikanan, penghijauan, hutan desa, pertanian tanaman holtikultura, Desa Mandiri Energi, dan lain-lain

\section{c. Smart economy}

Smart economy di sini memiliki target untuk merealisasikan aktivitas perekonomian di daerah agar dapat menjalankan tantangan serta beradaptasi di era informasi saat ini (Pemkab Blora, 2018). 
Tabel 3. Kegiatan smart economy tahun 2018-2019 dalam Masterplan

\begin{tabular}{|c|c|c|c|c|}
\hline NO & NAMA KEGIATAN & PELAKSANA & 2018 & 2019 \\
\hline 1 & Pengembangan Industri Kecil Menengah & DINPERINAKER & & v \\
\hline 2 & Expo Produk Unggulan Daerah & DINPERINAKER & v & v \\
\hline 3 & UMKM Expo & DINDAGKOPUKM & v & v \\
\hline 4 & $\begin{array}{l}\text { Peningkatan Angka Kebuntingan Sapi Induk } \\
\text { Melalui Pelayanan Insemenasi Buatan }\end{array}$ & DINAKIKAN & v & v \\
\hline 5 & Blora Kuncara & DINKOMINFO & v & v \\
\hline 6 & $\begin{array}{l}\text { Peningkatan Kesempatan Kerja Melalui } \\
\text { Pelatihan Berbasis Wirausaha dan Demand } \\
\text { Driven }\end{array}$ & DINPERINAKER & v & v \\
\hline 7 & $\begin{array}{l}\text { Peningkatan Kualitas Dan Produktivitas } \\
\text { Tenaga Kerja Melalui BLK }\end{array}$ & DINPERINAKER & v & v \\
\hline 8 & Pelatihan Pelaku Agribisnis & DIPERTAN & v & v \\
\hline 9 & Penyiapan Kesehatan Ternak & DINAKIKAN & v & v \\
\hline 10 & Lomba Ternak & DINAKIKAN & v & v \\
\hline 11 & Peremajaan Induk Ikan & DINAKIKAN & v & v \\
\hline 12 & Peningkatan SDM Petani Ikan & DINAKIKAN & v & v \\
\hline 13 & Pembentukan Bumdes Bersama & DPMD & & v \\
\hline 14 & E-retribusi (Pasar) & DINDAGKOPUKM & & v \\
\hline 15 & $\begin{array}{l}\text { Sistem Pembayaran Bumdes Terintegrasi } \\
\text { Dengan Bank }\end{array}$ & DPMD & v & v \\
\hline
\end{tabular}

Pada tabel 3, terdapat 15 kegiatan yang telah dilaksanakan sepanjang 20182019, dan salah satunya masuk dalam Quick Win, yakni aplikasi Blora Kuncara, sebuah aplikasi yang menyajikan profil berupa potensi-potensi yang ada di Kabupaten Blora sehingga memudahkan para pendatang maupun masyarakat lokal untuk mengakses informasi terkait Blora sekitarnya dan sudah bisa diunduh di playstore.

\section{d. Smart living}

Smart living memiliki tujuan guna melindungi hak taraf hidup masyarakat serta menciptakan kawasan tempat tinggal yang memadai, efisien serta nyaman (Pemkab Blora, 2018). Berikut adalah tabel kegiatan program-program smart living. 
Tabel 4. Kegiatan smart living tahun 2018-2019 dalam Masterplan

\begin{tabular}{|c|c|c|c|c|}
\hline NO & NAMA KEGIATAN & PELAKSANA & 2018 & 2019 \\
\hline 1 & $\begin{array}{l}\text { Peningkatan Peran Serta Masyarakat Dalam } \\
\text { Penataan Ruang }\end{array}$ & DPUPR & v & v \\
\hline 2 & Penanganan Kawasan Kumuh & DINRUMKIMHUB & $v$ & v \\
\hline 3 & $\begin{array}{l}\text { Penyusunan Peta Informasi Masyarakat } \\
\text { Kurang Gizi }\end{array}$ & DINKES & v & v \\
\hline 4 & Rumah Data Kampung KB & DPPKB & $v$ & v \\
\hline 5 & Sistem Informasi Gender dan Anak (SIGA) & DINSOSP3A & v & v \\
\hline 6 & $\begin{array}{l}\text { Pengembangan Media Promosi dan } \\
\text { Informasi Sadar Hidup Sehat }\end{array}$ & DINKES & v & v \\
\hline 7 & $\begin{array}{l}\text { Program Peningkatan Keselamatan Ibu } \\
\text { Melahirkan dan Anak }\end{array}$ & DINKES & v & $v$ \\
\hline 8 & PAB (Proyek Air Bersih) & DINRUMKIMHUB & $v$ & v \\
\hline 9 & $\begin{array}{l}\text { Pamsimas (Penyediaan Air Minum dan } \\
\text { Sanitasi Berbasis Masyarakat) }\end{array}$ & DINRUMKIMHUB & v & v \\
\hline 10 & $\begin{array}{l}\text { SIM RS (Database RS Seperti Obat-obatan, } \\
\text { DII) }\end{array}$ & RSUD Blora / Cepu & v & v \\
\hline 11 & SMS Gateway (Pendaftaran Online) & RSUD Blora / Cepu & v & v \\
\hline 12 & $\begin{array}{l}\text { Aplikasi Sedot A Mas (Sistem Pendaftaran } \\
\text { Online, Informasi Ketersediaan Tempat } \\
\text { Tidur, Aduan Masyarakat) }\end{array}$ & RSUD Blora & v & v \\
\hline 13 & $\begin{array}{l}\text { Peningkatan dan Pemeliharraan Jalan I dan } \\
\text { Jalan II }\end{array}$ & DPUPR & v & v \\
\hline 14 & $\begin{array}{l}\text { Pembangunan dan Rehabilitasi Jembatan I } \\
\text { dan Jembatan II }\end{array}$ & DPUPR & v & v \\
\hline 15 & Pemasangan Street Light PJU Smart System & DINRUMKIMHUB & & v \\
\hline
\end{tabular}

Terdapat 15 kegiatan dalam smart living yang menjadi tanggung jawab dari beberapa OPD seperti DPUPR (Dinas Pekerjaan Umum dan Penataan Ruang), DIMRUMKIMHUB (Dinas Perumahan Permukiman Perhubungan), DINKES (Dinas Kesehatan), DPPKB (Dinas Pengendalian Penduduk dan Keluarga Berencana), DINSOSP3A (Dinas Sosial Pemberdayaan Perempuan dan Perlindungan Anak) serta RSUD (Rumah Sakit Umum Daerah) Blora. Salah satunya dari kegiatan tersebut juga menjadi program Quick Win yaitu aplikasi Sedot A
Mas (Sistem Pendaftaran Online, Informasi Ketersediaan Tempat Tidur, Aduan Masyarakat)

\section{e. Smart society}

Target smart society dalam program Gerakan Menuju 100 Smart City, yakni untuk melaksanakan tatanan sosio teknis atau interaksi antara manusia dengan teknologi yang humanis dan aktif agar mencapai masyarakat dengan digital literasi yang tinggi, komunikatif, serta kreatif (Pemkab Blora, 2018). 
Tabel 5. Kegiatan smart society tahun 2018-2019 dalam Masterplan

\begin{tabular}{|c|c|c|c|c|}
\hline NO & NAMA KEGIATAN & PELAKSANA & 2018 & 2019 \\
\hline 1 & $\begin{array}{l}\text { Database Keberadaan Organisasi Masyarakat / } \\
\text { LSM }\end{array}$ & KESBANGPOL & v & v \\
\hline 2 & $\begin{array}{l}\text { Bapak Selamat (Bersama Perpustakaan Wujudkan } \\
\text { Sekolah Literasi Masyarakat) }\end{array}$ & DPK & & v \\
\hline 3 & $\begin{array}{l}\text { Pembangunan Database Sistem Kearsipan Untuk } \\
\text { Arsip Keluarga }\end{array}$ & DPK & & v \\
\hline 4 & $\begin{array}{l}\text { E Arsip Keluarga (KK, KTP, Akte, ljazah DII Berupa } \\
\text { Data Scan) }\end{array}$ & DPK & & v \\
\hline 5 & Pengembangan Desa Siaga Bencana & BPBD & & v \\
\hline 6 & Pelatihan Mitigasi Bencana & BPBD & & v \\
\hline 7 & Watter Supply & BPBD & & $v$ \\
\hline 8 & $\begin{array}{l}\text { Layanan Tanggap Darurat Terintegrasi (Publik } \\
\text { Safety Center 119) }\end{array}$ & DINKES & v & v \\
\hline
\end{tabular}

Pada tabel 5, kegiatan smart society baru dilaksanakan pada 2019 yang dinaungi oleh OPD-OPD Blora seperti Kesatuan Bangsa dan Politik (KESBANGPOL), Dinas Perpustakaan dan Kearsipan (DPK), Badan Penanggulangan Bencana Daerah (BPBD) dan Dinas Kesehatan (DINKES).

\section{f. Smart environment}

Smart environment mempunyai sasaran, yakni merealisasikan pembangunan berkelanjutan dengan teknologi sebagai pendukung dan menciptakan pengelolaan lingkungan yang ramah, konsisten, dan bertanggung jawab (Pemkab Blora, 2018).

Tabel 6. Kegiatan smart environment tahun 2018-2019 dalam Masterplan

\begin{tabular}{|c|c|c|c|c|}
\hline No & NAMA KEGIATAN & PELAKSANA & 2018 & 2019 \\
\hline 1 & Kampung Berhias & DLH & v & $\mathrm{v}$ \\
\hline 2 & Kampung Iklim & DLH & $\mathrm{v}$ & $\mathrm{v}$ \\
\hline 3 & Pengembangan Taman Kota & DINRUMKIMHUB & v & $\mathrm{v}$ \\
\hline 4 & $\begin{array}{l}\text { Peningkatan Jaringan Irigasi I, Peningkatan } \\
\text { Jaringan Irigasi II, Rehabilitasi/Pemeliharaaan } \\
\text { irigasi I, Rehabilitasi/Pemeliharaan Irigai II }\end{array}$ & DPUPR & $\mathrm{v}$ & $\mathrm{v}$ \\
\hline 5 & Blora Green Waste & DLH & $\mathrm{v}$ & $\mathrm{v}$ \\
\hline 6 & Satu Desa Satu Bank Sampah & DLH & & $\mathrm{v}$ \\
\hline 7 & Kampung Organik & DLH & $\mathrm{v}$ & $\mathrm{v}$ \\
\hline
\end{tabular}


Pada tabel 6, terdapat 7 kegiatan yang menunjang smart environment dalam rentang 2018-2019 dan dilaksanakan oleh OPD seperti Dinas Lingkungan Hidup (DLH), Dinas Perumahan Permukiman Perhubungan (DINRUMKIMHUB) serta Dinas Pekerjaan Umum dan Penataan Ruang (DPUPR).

Hasil temuan penelitian ini memiliki perbedaan dengan 2 penelitian sebelumnya, ditulis oleh Inayatul Ulya A dan Avinanta Tarigan berjudul "Mengukur Kesiapan Kota dalam Menerapkan Konsep Smart City Inisiatif (Studi Kasus: Kota Banjarmasin)" pada 2017 menerangkan terdapat 3 faktor enabler Garuda Smart City Model (GSCM) dalam menerapkan konsep smart city (SC) inisiatif. Faktor tersebut terdiri dari tata kelola SC, teknologi informasi dan komunikasi (TIK), dan manusia. Pada penelitian ini, model smart city yang digunakan oleh Kabupaten Blora adalah Smart Readines. Smart Readiness ini memiliki enabler sebagai landasan berupa potensi alamnya (nature) seperti sumber daya alamnya, lingkungan hidup maupun ekosistemnya namun enabler ini harus didukung dengan driver yakni struktur, infrastruktur serta suprastruktur. Untuk melengkapi enabler dan driver ini, dibutuhkan mediator untuk memfokuskan pembangunan smart city yang terdiri atas tradisi, interaksi serta inovasi.

Penelitian juga meneguhkan penelitian Utomo dan Hariadi pada 2016 yang menyatakan bahwa konsep smart city secara menyeluruh menurut IEEE Smart Cities.org meliputi smart governance, smart economy, smart mobility, smart environment, smart people, dan smart living. Masing-masing kota memiliki perbedaan dalam menerapkan konsep ini untuk pembangunan kotanya dengan beberapa strategi dan tantangan yang harus dihadapi. Meskipun begitu, riset ini menggunakan 6 dimensi dengan menambahkan dimensi smart branding serta smart society. Ini karena Kabupaten Blora mengikuti prosedur yang diinstruksikan oleh Kemenkominfo yang menerapkan konsep dari Smart Nation Citiasia

\section{KESIMPULAN}

Penelitian ini menyimpulkan bahwa keberhasilan Kabupaten Blora dalam membangun smart city tidak dapat dilepaskan dari strategi komunikasi yang efektif. Penelitian ini menunjukkan bahwa Kabupaten Blora telah sedapat mungkin mengimplementasikan tahapan strategi komunikasi, yang dimulai dari penelitian hingga pelaporan. Meskipun demikian, masih ada sejumlah hambatan.

Faktor penghambatnya di antaranya belum mengoptimalkan penggunaan media sosial untuk khalayak millenial, monitoring yang belum terkelola dengan baik, tujuan yang ingin dicapai secara keseluruhan belum terukur dengan baik, kapasitas dan kualitas SDM bagian IT yang belum maksimal, pesan atau informasi yang disampaikan hanya bersifat informatif saja, masih banyaknya masyarakat yang belum mengetahui program smart city ini sehingga sosialisasi harus terus dilakukan secara menyeluruh, pengguna media sosial yang lebih kritis menuntut Pemkab Blora untuk membuat konten yang lebih menarik.

Bagi lembaga terkait, penelitian menyarankan agar program Kabupaten Blora meningkatkan semua yang menjadi faktor pendorong dari gerakan smart city, yakni terus mengembangkan sektor agroindustry dan agroforestry demi terwujudnya visi smart city Kabupaten Blora. Selain itu, juga lebih meningkatkan sosialisasi program smart city untuk tahun 
ini dan tahun selanjutnya dengan media yang telah ditentukan terlebih di media sosial agar dapat menjangkau seluruh masyarakat Blora terutama millenial karena masyarakat juga memengaruhi keberhasilan program tersebut.

\section{DAFTAR PUSTAKA}

Cangara, H. (2013). Perencanaan Komunikasi. Rajagrafindo Persada.

Esabella, S. (2016). Menuju Konsep Smart City (Working Paper Makalah Disajikan Dalam Kuliah Tamu). https://www.researchgate.net/profile/Sh inta_Esabella2/publication/322303099_ Menu\%ogju_Konsep_Smart_City/links/ 5a527efda6fdcc7690026bba/MenujuKonsep-Smart

City.pdf?origin=publication_detail

Idrus, M. (2009). Metode Penelitian Ilmu Sosial, Pendekatan Kualitatif dan Kuantitatif. Erlangga.

Lianjani, A. (2018). Strategi Komunikasi Pemerintah Kota Tangerang Selatan dalam Mensosialisasikan Program Smart City [UIN Jakarta]. http://repository.uinjkt.ac.id/dspace /bitstream/123456789/41377/1/APR ILIA\%25 20LIANJANI-FDK.pdf
Mursalim, W. (2017). Implementasi Kebijakan Smart City di Kota Bandung. Jurnal Ilmu Administrasi Universitas Sangga Buana YPKP Bandung, 14(1).

Pemkab Blora. (2018). Masterplan Smart City Kabupaten Blora.

Purnomowati, W. (2014). Konsep Smart City dan Pengembangan Pariwisata di Kota Malang. Jurnal JIBEKA, 8(1).

Ulya, I., \& Tarigan, A. (2017). Mengukur Kesiapan Kota Dalam Menerapkan Konsep Smart City Inisiatif (Studi Kasus: Kota Banjarmasin). Journal Speed-Sentra Penelitian Engineering Dan Edukasi, 9(2).

Wijaya, S. I. (2015). Perencanaan dan Strategi Komunikasi dalam Kegiatan Pembangunan. Lentera Jurnal, XVIII(1), 58. https://journal.iainsamarinda.ac.id/index.php/lentera_j ournal/article/view/428 